\title{
Self-care Behavior and Frailty Syndrome among Elderly Patients with Heart Failure
}

\author{
Erna Rochmawati*, Sarah Amalia \\ Medical Surgical Nursing, School of Master in Nursing, Universitas Muhammadiyah Yogyakarta, Bantul, Indonesia
}

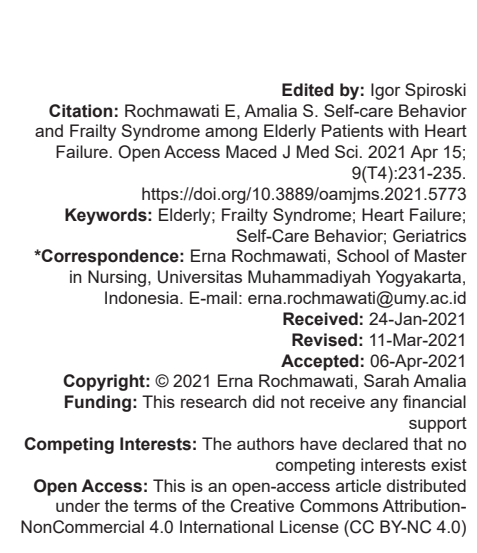

\section{Introduction}

Heart failure can be defined as a clinical complex syndrome because of structural and functional damage that decreases the ventricle function to pump blood to the whole body [1]. Heart failure cases increase every year. In the USA, the prevalence of heart failure in 2008 was 5.7 million people and increased in 2010 to 6.6 million people and will continually increase until 2030 [2]. In Indonesia, cardiovascular disease incidence in 2013 was $0.13 \%$ [3] and increased in 2018 to $1.5 \%$. Based on a national report, Yogyakarta Province was in the third position of heart failure after North Kalimantan and Gorontalo [4].

Heart failure is a chronic disease characterized by acute exacerbation, which can define the signs and symptoms as gradual or rapid change, resulting in urgent therapy. Therefore, this condition is the cause of rehospitalization in patients with heart failure. Since the prevalence of heart failure increased, the incidence of rehospitalization also improved [5]. Heart failure has become a significant health problem among communities because of high mortality, morbidity, and hospital costs. This clinical syndrome is related to functional capacity impairment and low quality of life. Mostly, patients with heart failure were elderly, and the risk of heart failure increased by around $80 \%$, constituting with aging [6].

Most patients with heart failure were elderly [7]. Overall, $80 \%$ of patients with heart failure were 65 -yearsold [8]. Elderly patients with heart failure have more complex comorbidity than younger patients. It is related to a decrease in functional capacity [6]. Therefore, frailty syndrome is defined as a syndrome of decreased functional capacity. Therefore, patients with heart failure, particularly the elderly, are often characterized by a vulnerability state due to the presence of several comorbidities and impaired functional capacity. The frailty syndrome component is assessed in multidomain from comorbidities. They include daily activities deficits, physical and psychosocial impairment.

Patients with heart failure are more at risk of falls and experiencing cognitive impairment due to cerebral hypoperfusion, progressing frailty, and disability [9]. Frailty syndrome is a crucial factor for bad prognosis in mortality, rehospitalization, and quality of life in heart failure patients. The impact of frailty syndrome can decrease self-care behavior and patients with heart failure [7]. 
Patients with heart failure diagnosed frailty syndrome need individual treatments, mainly support about self-care [8]. Self-care is an essential factor in preventing hospitalization and promoting positive health outcomes [10]. Based on Orem [11], three components of self-care are (a) universal self-care requisites related to daily living activities, such as water, air, hygiene, food, activity, rest, be alone and social interaction, and preventing hazard for life. (b) The developmental selfcare requisites are human needs for developing better treatment and improving individual ability to overcome development. (c) Health deviation requisites are selfcare needs, which is appropriate for the health problem. Recommendations self-care behavior for patients with heart failure consists of a low-salt diet, limiting the number of fluids, monitoring signs, and symptoms such as shortness of breath, swollen feet, activity intolerance, and contacting the doctor regularly [7].

Patients with heart failure who have frailty syndrome will have limitations in conducting self-care due to their daily activities. Self-care contributes to reducing rehospitalization and decompensation of disease [7].

This study aims to assess the correlation of self-care behavior with frailty syndrome in elderly patients with heart failure.

\section{Methods}

The study included 87 patients in the cardiology outpatient unit in two private hospitals (Figure 1). The data were collected from January 2020 to February 2020 and who had been diagnosed with heart failure. Inclusion criteria for the participants were diagnosed with heart failure, more than 60-years-old with all implications, patients visited cardiology outpatients, and accepted participants and cooperatives. Exclusion criteria consisted of patients with dementia withdraw from the study.

The researchers collected data, including demographic data, frailty index-40 questionnaire, selfcare heart failure index developed by Riegel et al. [12]. The self-care heart failure instrument comprised 20 questions about self-care maintenance [1-8], self-care management [9-13], and self-care confidence [14-20] with a Likert scale. The total score of the questionnaire is 80 . Lack of self-care is said to be inadequate if the total score is under 70 . In contrast, self-care is said to be adequate if the total score is more than 70. Frailty syndrome was assessed using the frailty index-40 questionnaires developed by Rockwood and Mitnitski [13]. The frailty state was categorized into three groups: Frailty index $\leq 80$ classified as robust/fit, $>0.08-<0.25$ as prefrail, and $\geq 0.25$ as frail. Statistic test using Spearman Rho was for testing the correlation between self-care behavior and frailty syndrome.

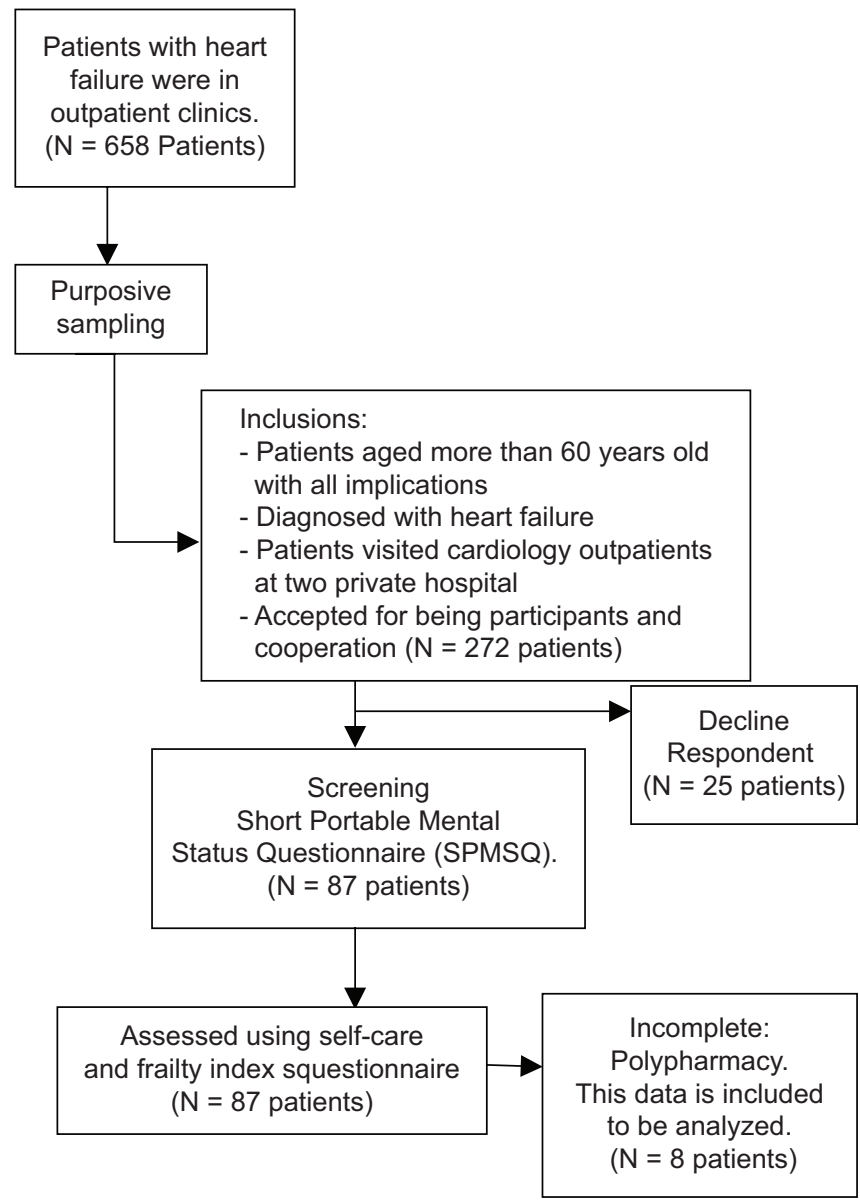

Figure 1: Participants selection

\section{Ethical considerations}

The ethic approval was granted by the ethics committees of the University of Aisyiyah with No. 954/ KEP-UNISA/XII/2019. Written informed consent was obtained from the subjects or their family members before the data collection. In presenting the results, coding to preserve confidentiality was employed.

\section{Results}

The characteristics of the patients included in the study are presented in Table 1. The mean age was 69 -years-old. Mostly, the gender of the respondents was male $(52.9 \%)$. The last education of subjects was a mostly elementary school (34.5\%). Most of them consumed five drugs $(45.9 \%)$, and they had one comorbidity $(59.8 \%)$. Bivariate analysis showed a correlation between gender with self-care behavior $(p=0.00)$ and polypharmacy with self-care behavior $(p=0.03)$. 
Table 1: Characteristic of the respondents

\begin{tabular}{|c|c|c|c|c|}
\hline \multirow[t]{2}{*}{ Characteristic } & \multicolumn{2}{|c|}{ Intervention group } & \multicolumn{2}{|c|}{ Control group } \\
\hline & $\mathrm{n}$ & $\%$ & $\mathrm{n}$ & $\%$ \\
\hline \multicolumn{5}{|l|}{ Gender } \\
\hline Female & 21 & 84 & 22 & 88 \\
\hline Male & 4 & 16 & 3 & 12 \\
\hline \multicolumn{5}{|l|}{ Age (years) } \\
\hline $26-35$ & 7 & 28 & 3 & 12 \\
\hline $36-45$ & 7 & 28 & 13 & 52 \\
\hline $46-55$ & 6 & 24 & 6 & 24 \\
\hline $56-65$ & 4 & 16 & 3 & 12 \\
\hline$>65 \mathrm{y}$ & 1 & 4 & 0 & 0 \\
\hline \multicolumn{5}{|l|}{ Relationship with patient } \\
\hline Spouse & 11 & 44 & 7 & 28 \\
\hline Children & 9 & 36 & 15 & 60 \\
\hline Parents & 1 & 4 & 0 & 0 \\
\hline Sibling & 3 & 12 & 2 & 8 \\
\hline Other (niece) & 1 & 4 & 1 & 4 \\
\hline \multicolumn{5}{|c|}{ Support from other family members } \\
\hline Yes & 18 & 72 & 21 & 84 \\
\hline None & 7 & 28 & 4 & 16 \\
\hline \multicolumn{5}{|l|}{ Employment } \\
\hline Government employee & 1 & 4 & 0 & 0 \\
\hline Private employee & 5 & 20 & 2 & 8 \\
\hline Self-employed & 5 & 20 & 3 & 12 \\
\hline Housewife & 13 & 52 & 19 & 76 \\
\hline Other & 1 & 4 & 1 & 4 \\
\hline \multicolumn{5}{|l|}{ Length of caregiving } \\
\hline$<1$ year & 7 & 28 & 2 & 8 \\
\hline$>1$ year & 18 & 72 & 23 & 92 \\
\hline \multicolumn{5}{|l|}{ Patient's medical diagnose } \\
\hline DM & 7 & 28 & 5 & 20 \\
\hline Stroke & 4 & 16 & 5 & 20 \\
\hline Canker & 4 & 16 & 6 & 24 \\
\hline COPD & 6 & 24 & 6 & 24 \\
\hline $\mathrm{CHF}$ & 4 & 16 & 3 & 12 \\
\hline
\end{tabular}

Based on Table 2, the study result shows that most respondents have inadequate self-care behavior $(98.9 \%)$, and only one subject has adequate selfcare behavior $(1.1 \%)$. Most of the subjects are pre-fail $(71.3 \%)$, robust is $20.7 \%$, and frailty is $8.0 \%$. The mean score of self-care behavior is 48.70 , and the frailty stage is on pre-frail, with the mean score is 0.14 .

Table 2: Self-care behavior and frailty syndrome in elderly patients with heart failure $(n=87)$

\begin{tabular}{lllll}
\hline Variable & Frequency $(\mathrm{n})$ & Percentage & Mean $(\mathrm{SD})$ & Range \\
\hline Self-care behavior & & & & \\
$\quad$ Adequate $(>70)$ & 1 & 1.1 & $48.7(5.95)$ & $36-71$ \\
$\quad$ Inadequate $(<70)$ & 86 & 98.9 & & \\
Frailty syndrome & & & & \\
$\quad$ Robust & 18 & 20.7 & $0.14(0.07)$ & $0.04-0.41$ \\
$\quad$ Pre-frail & 62 & 71.3 & & \\
$\quad$ Frailty & 7 & 8.0 & & \\
\hline
\end{tabular}

Table 3 shows no correlation between total self-care behavior and frailty syndrome $(p>0.05)$. Each aspect of self-care behavior is also not significantly associated with frailty syndrome.

Table 3: Correlation between self-care behavior and frailty syndrome in elderly patients with heart failure $(n=87)$

\begin{tabular}{lll}
\hline Variable & Frailty syndrome & \\
\cline { 2 - 3 } & Spearman $(\mathrm{r})$ & Significance \\
\hline Self-care & 0.13 & 0.20 \\
Self-care maintenance & 0.01 & 0.87 \\
Self-care management & 0.20 & 0.05 \\
Self-care confidence & 0.02 & 0.85 \\
\hline
\end{tabular}

\section{Discussion}

Based on Table 1, the present study reveals that respondent' mean age is 69-years-old. It is related to Díez-Villanueva and Alfonso [6], who found that $80 \%$ of patients with heart failure were elderly and would develop due to increased age. Comorbidity problems in the elderly were more complicated than in younger. Apart from physical limitations, it also created troublesome for the elderly to do physical activity. The majority gender of respondents is male. Heart failure mostly happened to males due to unhealthy lifestyles, such as smoking, unhealthy diet, and lack of exercise, causing an increased risk of heart failure [14]. The study shows that the majority of the respondents were graduated from elementary school.

Education is a factor that affects the patient in understanding the course of the illness suffered by himself. It relates to the level of knowledge the patient has. The higher the patients' knowledge, the higher the incidence of heart failure prevention [6]. Table 1 displays the mean of drugs consumed by respondents around five drugs. The type of drugs consists of diuretic (furosemide and spironolactone), beta-blocker (bisoprolol), ice inhibitor (candesartan, amlodipine, and Ramipril), and oxygen to maintain the health status of the respondent from complications.

Table 1 shows that gender is related to self-care behavior and has no relation to frailty syndrome. Based on the interview, respondents still did smoking, skipped taking medication, and had no regular adherence to the clinic, making inadequate self-care behavior in patients, particularly in men. In the woman, subjects mostly had adequate self-care behavior. Based on Mlynarska et al. [7], women had high adherence to medication in conservative therapy, including pharmacological therapy and lifestyle changes.

Table 1 reveals that polypharmacy is related to self-care behavior and has no correlation with frailty syndrome. Following by Setiati et al. [15], they uncovered that respondents' total drugs were more than five drugs. Elderly patients with heart failure who have comorbidities need complex medication. Many drugs consumed can affect patients' self-care behavior in decreased adherence to pharmacological therapy [16]. Patients with heart failure experience impairment of cerebral perfusion that causes frailty syndrome and develop comorbidities. Another study found that most elderly patients with heart failure had frailty syndrome, which caused poor prognosis [17].

Based on Table 2, the present study shows inadequacy in self-care behavior. Other research revealed that inadequacy self-care behavior in elderly patients with heart failure was due to an increase of age that the ability to respond and recognize signs and symptoms would decrease [18]. This research indicated that the component that had the lowest total score was self-care management. This component discussed the consumption of extra diuretic drugs if signs and symptoms appeared. Inadequate self-care behavior in elderly patients with heart failure can increase the disease's severity, rehospitalization, and decreased quality of life. Notably, the elderly were commonly more than 70-years-old [7]. 
According to Attaallah et al. [18], the factors that determined inadequate self-care behavior in subjects were the increasing age and comorbidities, so the body's physical and psychological functioning would decrease. Physical factors consisted of cognitive impairment and speed of thinking and remembered, such as decreased response and managed signs and symptoms. Psychological factors included depression due to lack of family support to manage their health status and do self-care behavior, as suggested. Both effects influenced adherence for doing self-care behavior in patients with heart failure.

Culture also could influence self-care behavior [19]. Experience, practice, and beliefs of subjects would influence subjects to do self-care [7]. Another factor can influence self-care behavior, namely, a low acceptance level of disease, which worsens self-care behavior. For patients with heart failure, selfcare behavior is related to polypharmacy affecting multimorbidity [7]. Uchmanowicz et al. [8] revealed that adherence behavior in consuming drugs in self-care could decrease the disease's decompenzation. It may be preventing factors for rehospitalization for patients with heart failure.

Univariate analysis in Table 2 reveals that most of the subjects are pre-frail. These results are in line with Setiati et al. [15], who found the subjects were also pre-frail around $70.4 \%$. The pre-frail stage could develop into frailty syndrome because the risk was 2,7 fold in more than 70-years-old. This research follows [8], which showed that elderly patients with heart failure mostly experienced frailty syndrome. Health conditions of patients with heart failure who diagnosed with frailty syndrome were more vulnerable than other patients. Frailty syndrome caused rehospitalization, mortality, and decreased quality of life.

Table 3 shows no correlation between selfcare behavior and frailty syndrome. In this research, the majority of subjects were in the pre-frail stage. This research utilized frailty indexes to see multidomain, including health deficits, functional deficits, and psychosocial deficits. The interview showed that respondents experienced health deficits related to comorbidities and functional deficits in the elderly, while the patient had no experience of psychosocial deficits due to the socializing culture of Indonesian. It caused no correlation with self-care behavior.

Based on Table 3, the self-care component consists of self-care management, self-care maintenance, and self-care confidence that do not correlate with frailty syndrome. It was because subjects showed inadequate self-care behavior and were mostly in the pre-frail stage. According to Rockwood and Mitnitski [13], seen from multidomain, individuals in the pre-frail stage experienced $20-35 \%$ of deficits. Inadequate self-care behavior caused the pre-frail stage in elderly patients with heart failure.
Based on interviews, subjects with older age lacked self-care management because of decreased physical ability and more frequent symptoms. Based on gender, females were better in three components than males because they had better adherence to medication in undergoing self-care behavior. More of the subjects' drugs had better self-care management and a lack of self-care confidence. Polypharmacy in patients became an indication that they had complex comorbidities. It was caused by a lack of confidence in patients when doing self-care behavior. Based on comorbidities, the more comorbidities the subjects have, the better selfcare management, and self-care maintenance will be. It is particularly in adherence to medication and taking treatment for reducing symptoms.

\section{Conclusion}

A mostly inadequate self-care behavior and the pre-frail stage in elderly patients with heart failure were found. There were no correlations between self-care behavior and frailty syndrome in elderly patients with heart failure. It was because there were no psychosocial deficits found in elderly patients with heart failure.

\section{References}

1. Sharon Ann Hunt, American College of Cardiology; American Heart Association Task Force on Practice Guidelines (Writing Committee to Update the 2001 Guidelines for the Evaluation and Management of Heart Failure). ACC/AHA 2005 guideline update for the diagnosis and management of chronic heart failure in the adult: A report of the American college of cardiology/American heart association task force on practice guidelines (writing committee to update the 2001 guidelines for the evaluation and management of heart failure). J Am Coll Cardiol. 2005;46(6):e182. https://doi.org/10.1161/cir.0000000000000460

PMid:16168273

2. Roger VL, Go AS, Lloyd-Jones DM, Benjamin EJ, Berry JD, Borden WB, et al. Heart disease and stroke statistics-2012 update: A report from the American heart association. Circulation. 2012;125(1):e2-220.

PMid:22179539

3. Riskesdas. Riset Kesehatan Dasar, Badan Penelitian dan Pengembangan Kesehatan Kementrian Kesehatan; 2013.

4. Riskesdas. In: Bpdpkk K, editor. Hasil Utama Riskesdas. Indonesia: Kementerian Kesehatan; 2018.

5. Roger VL. Epidemiology of heart failure. Cir Res. 2013;113(6):646-59.

PMid:23989710

6. Díez-Villanueva P, Alfonso F. Heart failure in the elderly. J Geriatr Cardiol. 2016;13(2):115-7.

PMid:27168735

7. Mlynarska A, Golba KS, Mlynarski R. Capability for self-care of 
patients with heart failure. Clin Interv Aging. 2018;13:1919-27. https://doi.org/10.2147/cia.s178393

PMid:30349210

8. Uchmanowicz I, Młynarska A, Lisiak M, Kałużna-Oleksy M, Wleklik M, Chudiak A, et al. Heart failure and problems with frailty syndrome: Why it is time to care about frailty syndrome in heart failure. Card Fail Rev. 2019;5(1):37-43. https://doi. org/10.15420/cfr.2018.37.1

PMid:30847244

9. Singh $\mathrm{M}$, Stewart $\mathrm{R}$, White $\mathrm{H}$. Importance of frailty in patients with cardiovascular disease. Eur Heart J. 2014;35(26):1726-31. https://doi.org/10.1093/eurheartj/ehu197

PMid:24864078

10. Asadi P, Ahmadi S, Abdi A, Shareef $\mathrm{OH}$, Mohamadyari T, Miri J. Relationship between self-care behaviors and quality of life in patients with heart failure. Heliyon. 2019;5(9):e02493. https:// doi.org/10.1016/j.heliyon.2019.e02493

PMid:31687585

11. Orem DE, Taylor SG, Renpenning KM. Nursing Concepts of Practice; 1995.

12. Riegel B, Lee CS, Dickson VV, Carlson B. An update on the selfcare of heart failure index. J Cardiovasc Nurs. 2009;24(6):485-97. PMid: 19786884

13. Rockwood K, Mitnitski A. Frailty in relation to the accumulation of deficits. J Gerontol A Biol Sci Med Sci. 2007;62(7):722-7.

PMid: 17634318
14. Uchmanowicz I, Wleklik M, Gobbens RJ. Frailty syndrome and self-care ability in elderly patients with heart failure. Clin Interv Aging. 2015;10:871-7. https://doi.org/10.2147/cia.s83414 PMid:26028966

15. Setiati S, Laksmi PW, Aryana IS, Sunarti S, Widajanti N, Dwipa L, et al. Frailty state among Indonesian elderly: Prevalence, associated factors, and frailty state transition. BMC Geriatr. 2019;19(1):182. https://doi.org/10.1186/s12877-019-1198-8 PMid:31269921

16. Mastromarino V, Casenghi M, Testa M, Gabriele E, Coluccia R, Rubattu S, et al. Polypharmacy in heart failure patients. Curr Heart Fail Rep. 2014;11(2):212-9. https://doi.org/10.1007/ s11897-014-0186-8

PMid:24493574

17. Wang X, Zhou C, Li Y, Li H, Cao Q, Li F. Prognostic value of frailty for older patients with heart failure: A systematic review and meta-analysis of prospective studies. Biomed Res Int. 2018;2018:8739058. https://doi.org/10.1155/2018/8739058 PMid:30426017

18. Attaallah S, Klymko K, Hopp FP. Self-care among older adults with heart failure. Gerontol Geriatr Med. 2016;2:1-23.

PMid:28680943

19. Jiang RS, Wu SM, Che HL, Yeh MY. Cultural implications of managing chronic illness: Treating elderly Chinese patients with heart failure. Geriatr Nurs. 2013;34(3):199-203. https://doi. org/10.1016/j.gerinurse.2013.02.002

PMid:23473648 